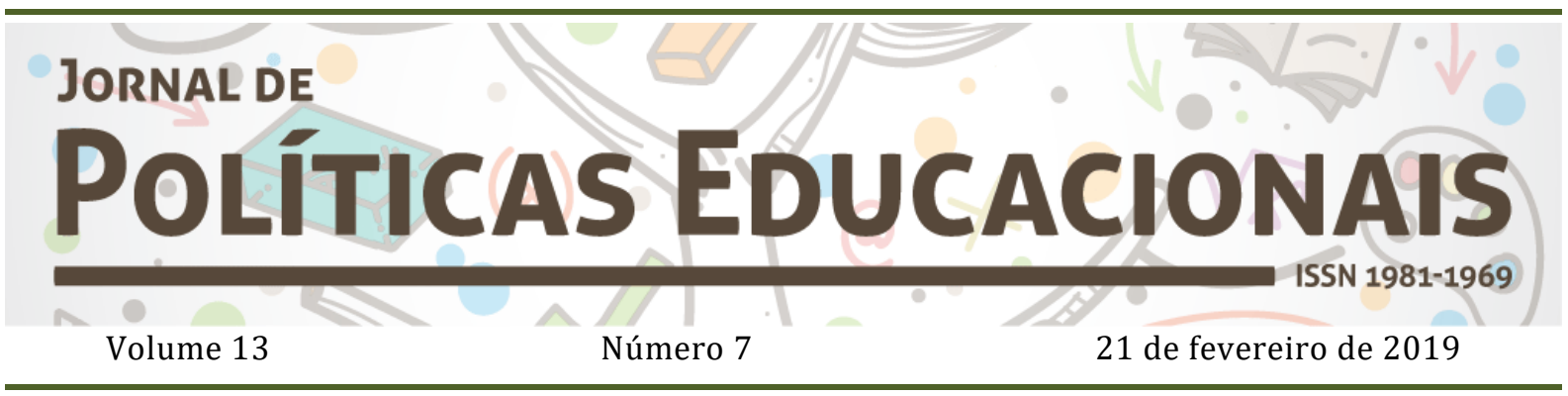

\title{
A produção acadêmica em políticas para a educação infantil no Brasil (2000-2010)
}

\section{Academic production in policies for early childhood education in Brazil (2000-2010)}

\section{La producción académica en políticas para la educación infantil en Brasil (2000-2010)}

\author{
Maria Aparecida Guedes Monção ${ }^{1}$ \\ Syomara Assuite Trindade ${ }^{2}$
}

Citação: MONÇÃO, M. A. G.; TRINDADE, S. A. A produção acadêmica em políticas para a educação infantil no Brasil (2000-2010). Jornal de Políticas Educacionais. V. 13, n. 7. Fevereiro de 2019.

http://10.5380/jpe.v12i0.64423

\section{Resumo}

O objetivo deste artigo é mapear os estudos em políticas educacionais na área da educação infantil, em teses e dissertações, no período de 2000 a 2010. Trata-se de uma pesquisa de revisão, que analisou 57 resumos, buscando sistematizar a produção e apresentar as principais conclusões. A maior parte dos trabalhos analisados versa sobre a ampliação da oferta após a incorporação da educação infantil na educação básica. Conclui-se que, apesar dos esforços empreendidos pelo poder público, as vagas ainda são insuficientes e que a adoção de preceitos neoliberais na implementação das políticas afeta sua qualidade, especialmente com a manutenção do atendimento conveniado e a precarização das condições de trabalho dos profissionais.

Palavras-chave: Políticas educacionais; Educação infantil; Estudos de revisão.

\footnotetext{
Abstract

The purpose of this article is to map the studies in educational policies in the field of early childhood education in theses and dissertations- from 2000 to 2010. It consists of a review research, which analyzed

${ }^{1}$ Doutora em Educação pela Universidade de São Paulo. Professora e Pesquisadora do Programa de PósGraduação em Educação (PPGE) da Universidade Estadual de Campinas (UNICAMP). E-mail: maguedes@unicamp.br

${ }^{2}$ Doutora em Educação pela Universidade Federal da Bahia. Professora e pesquisadora do Departamento de Educação da Universidade Estadual de Feira de Santana (UEFS).

E-mail: syo assuite@yahoo.com.br
} 
57 abstracts, aiming to systematize the production and present the key findings. Most of the analyzed studies address the expansion of the offer after the incorporation of early childhood education into basic education. It is concluded that, in spite of the government efforts, vacancies are still insufficient and that the adoption of neoliberal precepts in the implementation of policies affects the school quality, particularly due to the maintenance of contracted service and the precariousness of the working conditions to education workers.

Keywords: Educational policies; Childhood education; Review studies.

\section{Resumen}

El objetivo del artículo es mapear los estudios en políticas educativas en el área de la educación infantil en tesis y disertaciones en el período de 2000 a 2010. Se trata de una investigación de revisión, que analizó 57 resúmenes, buscando sistematizar la producción y presentar las principales conclusiones. La mayor parte de los trabajos analizados versa acerca de la ampliación de la oferta después de la incorporación de la educación infantil en la educación básica. Se concluye que, a pesar de los esfuerzos emprendidos por el poder público, las matrículas todavía son insuficientes y que la adopción de preceptos neoliberales en la implementación de las políticas afecta su calidad, especialmente con el mantenimiento de la asistencia con convenio y la precarización de las condiciones de trabajo de los profesionales.

Palabras clave: Políticas educativas; Educación Infantil; Estudios de revisión.

\section{Introdução}

No Brasil, os avanços na área da educação infantil foram impulsionados por conquistas legais cujo marco inicial foi a Constituição Federal de 1988 (CF/88), que estabelece como dever do Estado "o atendimento em creches e pré-escolas às crianças de 0 a 6 anos" (BRASIL, 1988, art. 208, inciso IV). Em 1996, com a promulgação da Lei de Diretrizes e Bases da Educação Nacional (LDB) no 9.394/96 (BRASIL, 1996), ocorreu um amplo processo de mudanças nas instituições de educação infantil. Situadas ao lado da pré-escola, as creches foram integradas ao sistema de ensino, compondo a primeira etapa da educação básica.

Dez anos após a promulgação da LDB, a Lei nº 11.274/2006 modificou a duração do ensino fundamental para nove anos, com matrícula obrigatória aos 6 anos de idade (BRASIL, 2006) e atendimento educacional em creches e pré-escolas para crianças de 0 a 5 anos e 11 meses. Em seguida, a Emenda Constitucional no 59/2009 (BRASIL, 2009) tornou obrigatória a matrícula de crianças a partir dos 4 anos, e ao município a disponibilização de vagas em estabelecimentos públicos para toda a demanda nessa faixa etária, conforme estabelece o art. 212 da CF/88 acerca da responsabilidade prioritária dos municípios com a educação infantil.

Ao contrário do que ocorreu no processo de inserção da educação infantil na $\mathrm{CF} / 88$, tanto a obrigatoriedade da matrícula das crianças de 6 anos no ensino fundamental quanto a da frequência na escola a partir dos 4 anos não se pautaram nos estudos da área ou em reivindicações dos movimentos sociais, mas partiram de 
demandas de ordem política e econômica, revelando que o campo de educação infantil constitui uma arena de diferentes interesses.

A história da educação infantil brasileira é marcada pela permanente atuação de profissionais, pesquisadores e movimentos sociais, que lutam incansavelmente para garantir a constituição de uma política pública democrática e de qualidade no atendimento às crianças de 0 a 5 anos e 11 meses, considerando os direitos das crianças e suas famílias como ponto de partida. Entretanto, apesar dos constantes esforços, a trajetória das políticas para a primeira infância é permeada de avanços e recuos, especialmente pela tendência histórica do Estado em esquivar-se da responsabilidade pela educação das crianças pequenas - particularmente 0 a 3 anos - como uma demanda pública e pela insuficiência de recursos financeiros destinados a essa etapa da educação básica.

Nesse sentido, a temática da qualidade da oferta é pautada desde a década de 1970, momento em que as creches e pré-escolas começaram a ser objeto de análise. De acordo com Rosemberg (2014, p. 170), diferentemente dos países do Hemisfério Norte, no Brasil o delineamento do debate a respeito da qualidade da oferta da educação infantil "tem focalizado o ordenamento legal e político, condições mínimas indispensáveis para se proporem estratégias de avaliação visando atingirem-se padrões de qualidade". Essa focalização se dá especialmente pelo enfrentamento constante contra a perspectiva de um atendimento desprovido de condições básicas para o bemestar físico e emocional de bebês e crianças pequenas, particularmente das camadas pobres da sociedade.

As modificações nos marcos legais impactaram diretamente as práticas pedagógicas no interior das unidades de educação infantil e a política pública de educação infantil; contudo, apesar da legislação avançada, ainda não é possível dizer que temos implementada uma educação infantil brasileira democrática e de qualidade. Segundo Rosemberg (2014, p. 174), o grande desafio atual para a área:

[...] não depende de melhores diretrizes ou normatizações mais amplas e abrangentes, mas sim enfrentar o descompasso entre esse ideal, contemporâneo e sofisticado, o real da prática cotidiana, o desafio entre o normatizado [...] e as condições sociais, políticas, econômicas e culturais que geram uma sociedade e uma Educação Infantil ainda intensamente discriminatórias: de classe, gênero, raça, religião, localização e idade. 
Pode-se dizer, pela trajetória da educação infantil brasileira, que o desafio explicitado por Rosemberg (2014) é o que tem impulsionado e fortalecido a atuação dos fóruns de educação infantil no monitoramento das políticas, como também a atuação de profissionais e pesquisadores comprometidos com o avanço e a qualificação da produção de conhecimento sobre a educação coletiva de bebês e crianças pequenas em creches e pré-escolas.

De acordo com Rocha, Silva Filho e Strenzel (2001), a ampliação de pesquisas na área foi impulsionada pela expansão do atendimento a partir das décadas de 1980 e 1990, período em que ficou latente a necessidade de ampliar as temáticas dos estudos na área, incluindo a dimensão pedagógica, ancorada numa visão crítica sobre o cotidiano das instituições de educação infantil, sua realidade e diferentes contextos. 0 desafio da nova área de pesquisa traz a necessidade de estudos do tipo levantamento, que permitem compreender de maneira mais complexa as diferentes formas de atendimento.

Nessa direção, destacamos também que, diante do novo ordenamento legal, os sistemas de ensino precisaram adequar-se às exigências regulatórias das publicações normativas, orientadoras das políticas educacionais, em nível nacional, estadual e municipal, para o atendimento das crianças pequenas. Tais publicações dizem respeito a: expansão do atendimento, elaboração de propostas pedagógicas ou curriculares, regimento, gestão e financiamento, formação inicial e continuada de professores e carreira docente, qualidade da oferta, autorização, supervisão e fiscalização das instituições de educação infantil pelo respectivo sistema, formulação e implementação de políticas públicas. As demandas para a política pública transformam-se concomitantemente em demandas para as pesquisas na área.

A intensificação da presença da primeira etapa da educação básica na produção acadêmica é notória, não só no campo das políticas educacionais brasileiras, mas também no campo pedagógico e das relações educativas travadas nas instituições de educação infantil em suas dimensões contextuais (ROCHA; SILVA FILHO; STRENZEL, 2001).

Entretanto, apesar do aumento da produção sobre educação infantil, na revisão de literatura efetuada para este artigo, constatou-se a existência de poucas pesquisas do tipo mapeamento da produção científica nacional em educação infantil. Os estudos encontrados foram: CAMPOS; HADDAD, 1992; ROCHA, 1999; ROCHA; SILVA FILHO; 
STRENZEL, 2001; STRENZEL, 2000. Tais estudos contribuem para delinear uma visão abrangente sobre a produção científica na área, fornecendo indicadores de análise que figuram antes e após as alterações legais e, apesar de partirem de delimitações temporais e suportes textuais diferentes, seus resultados muitas vezes se entrecruzam.

Campos e Haddad (1992) analisaram as contribuições das publicações dos Cadernos de Pesquisa, da Fundação Carlos Chagas, sobre a criança pequena no período de 1970 a 1990, dando visibilidade às temáticas que aparecem nesses estudos: psicologia do desenvolvimento; políticas e demandas sociais; pesquisa histórica; papel da sociedade civil e do Estado; expansão e qualidade do atendimento em creches e préescolas. Os resultados mostram a presença de macroanálises sobre os elementos históricos e políticos que constituíram as políticas para a infância e contribuíram na definição de pressupostos comuns para possibilitar uma nova análise dos estudos sobre desenvolvimento infantil no contexto em que ele ocorre, destacando a creche como espaço de pesquisa e ambiente favorável à socialização da criança. Em contrapartida, no período analisado houve a secundarização dos aspectos que impactam diretamente a estrutura das vivências cotidianas das crianças em creches e pré-escolas.

Faria (2005) assinala o protagonismo da Fundação Carlos Chagas ao inaugurar e solidificar a pesquisa sobre as crianças de 0 a 6 anos no cenário das políticas públicas, tendo papel importante na formulação dos conteúdos das políticas para essa faixa etária na CF/88, na LDB/96 e na criação da Coordenadoria de Educação Infantil, em 1992.

Rocha (1999), Rocha, Silva Filho e Strenzel (2001) e Strenzel (2000) mapearam a produção acadêmica brasileira. Os temas encontrados no conjunto da produção dos autores foram: políticas e ações sociais da infância e educação infantil; estudos de caráter histórico; contextos socioculturais e de relações entre adultos e crianças; desenvolvimento infantil e aprendizagem na perspectiva sócio-histórica; estudos a partir da escuta de crianças; currículo, orientações das práticas pedagógicas e formação de professores. De acordo com Rocha, Silva Filho e Strenzel (2001), a heterogeneidade dos assuntos pesquisados favorece a abordagem dos diferentes aspectos que compõem a educação das crianças de 0 a 6 anos, o que representa o avanço da produção e a consolidação do campo de pesquisa na educação infantil. Ademais, Rocha (1999) indica que poucas pesquisas deram voz à criança pequena e Strenzel (2000) assinala que os estudos enfatizaram as práticas pedagógicas e a formação de profissionais. 
0 presente trabalho caracteriza-se como um estudo de revisão de produção acadêmica, com o intuito de apresentar os elementos gerais das pesquisas, evidenciando as principais conclusões, de modo a somar-se a outros estudos e promover uma sistematização do conhecimento já instituído (VOSGERAU; ROMANOWSKI, 2014). 0 objetivo é mapear a produção acadêmica sobre políticas educacionais na área da educação infantil, em teses e dissertações no Brasil, no período de 2000 a 2010.

Esta investigação é fruto da análise dos resumos dos trabalhos sobre educação infantil que compõem o banco de dados da pesquisa $A$ produção acadêmica em políticas educacionais no Brasil: características e tendências, 2000-2010 (SILVA, 2014). A pesquisa foi financiada pela Coordenação de Aperfeiçoamento de Pessoal de Nível Superior (CAPES) e envolveu um grupo de pesquisadores de sete instituições de ensino superior públicas do Brasil. 0 estudo reuniu 1.283 teses e dissertações relacionadas às políticas educacionais no Brasil, defendidas em programas de pós-graduação em Educação que alcançaram o conceito 5 ou mais na avaliação trienal da Capes, concluída em 2010, abarcando um total de 20 universidades.

Do referido banco de dados, foram selecionados 145 trabalhos, com os descritores "educação infantil”, "creche”, "criança” e "infância”. Após leitura criteriosa dos 145 resumos, foram selecionados 57 que explicitamente se referem às políticas de educação infantil.

Ao longo do artigo serão apresentados os dados dos estudos selecionados referentes a filiação institucional, cidades onde foram realizadas as pesquisas, ano de defesa dos trabalhos, natureza (dissertação ou tese), temas e principais conclusões.

\section{A educação infantil e os resultados indicados nas teses e dissertações}

A busca no banco de dados que subsidiou este estudo revelou que apenas 57 dos 1.283 trabalhos referem-se a estudos sobre as políticas na área da educação infantil, o equivalente a $4,44 \%$ do total de pesquisas com interface com as políticas educacionais realizadas no período de 2000 a 2010 nas universidades selecionadas. Tal percentual indica que essa etapa da educação básica ainda ocupa lugar secundário nos estudos da área educacional, apesar de sua crescente produção, apontada nos estudos de mapeamento realizados por Rocha (1999), Rocha, Silva Filho e Strenzel (2001) e Strenzel (2000). 
Rocha, Silva Filho e Strenzel (2001) constatam o fortalecimento da pesquisa na área a partir do final da década de 1980, tanto em periódicos nacionais quanto em dissertações e teses, embora em índices percentuais o tema tenha correspondido a apenas 5\% da produção em Educação, no período 1983 a 1996. Segundo os autores, esse aumento é notadamente maior nos cursos de mestrado.

Os achados da presente pesquisa confirmam a predominância das dissertações de mestrado também no período de 2000 a 2010. Como mostra o Gráfico 1, 77,19\% das produções que tratam de educação infantil são dissertações e 22,81\% são teses.

Gráfico 1 - Natureza da pesquisa: mestrado e doutorado

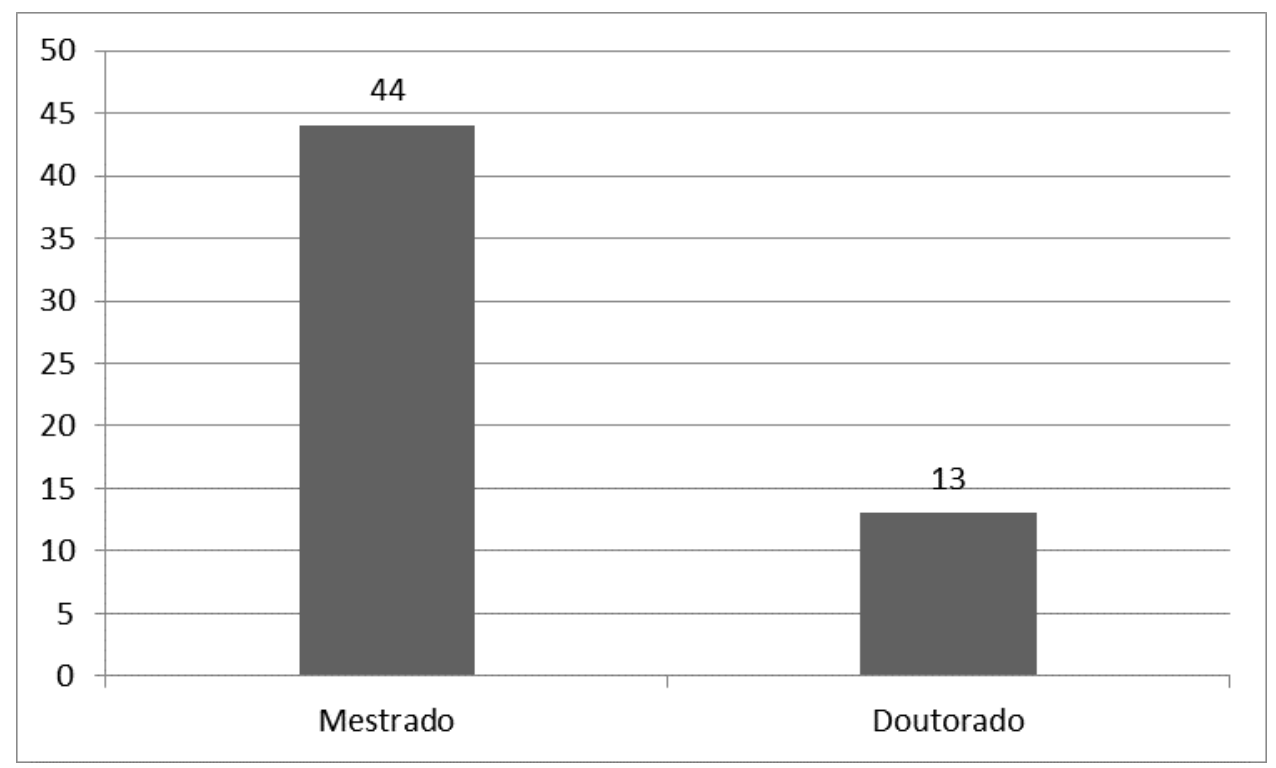

Fonte: SILVA (2014)

A ampliação de estudos no âmbito do doutorado é um desafio para a consolidação da área e pode contribuir para o aprofundamento sobre a especificidade do atendimento educacional de bebês e crianças pequenas no planejamento, implementação e avaliação de políticas, especialmente porque nessa etapa educacional tanto a estrutura e a gestão das instituições quanto a prática pedagógica assumem características muito diferenciadas de outras etapas da educação básica, particularmente pela necessária integração entre cuidado e educação, compartilhamento da educação com as famílias e centralidade das interações e brincadeiras com eixo da proposta curricular (CONSELHO NACIONAL DE EDUCAÇÃO, 2009). 
De modo geral, os dados sobre o ano de defesa dos trabalhos analisados, como pode ser visualizado no Gráfico 2, informam que a pesquisa em políticas de educação infantil está em processo de crescimento, o que já foi assinalado anteriormente.

Gráfico 2 - Ano de defesa

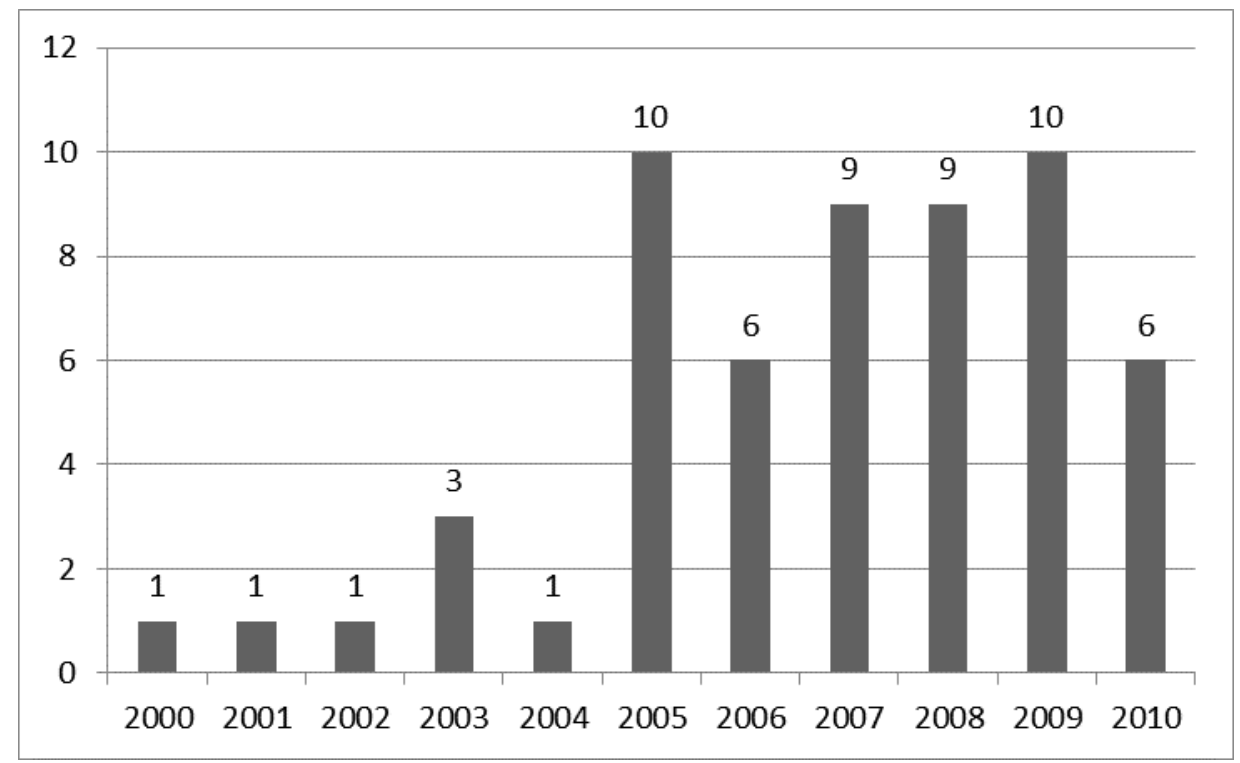

Fonte: SILVA (2014)

Entre 2000 e 2004 foi produzido um total de sete trabalhos e se nota uma estabilização dos números da produção, com variação em 2003. A partir de 2005, há aumento da produção na área, cuja média passa a ser entre seis e dez trabalhos por ano, a maior parte deles destinada à análise da expansão da oferta.

Os 57 trabalhos foram realizados em 17 universidades brasileiras, sendo 14 públicas e três privadas; 54 correspondem a pesquisas realizadas em programas de pósgraduação das Regiões Sul e Sudeste, totalizando 94,74\%. A maior produção de conhecimentos sobre política de educação infantil concentra-se nas seguintes instituições: Universidade Estadual de Campinas, com 11 trabalhos; Universidade de São Paulo, Universidade Federal de Minas Gerais e Universidade Federal do Rio Grande do Sul, com seis trabalhos cada. 


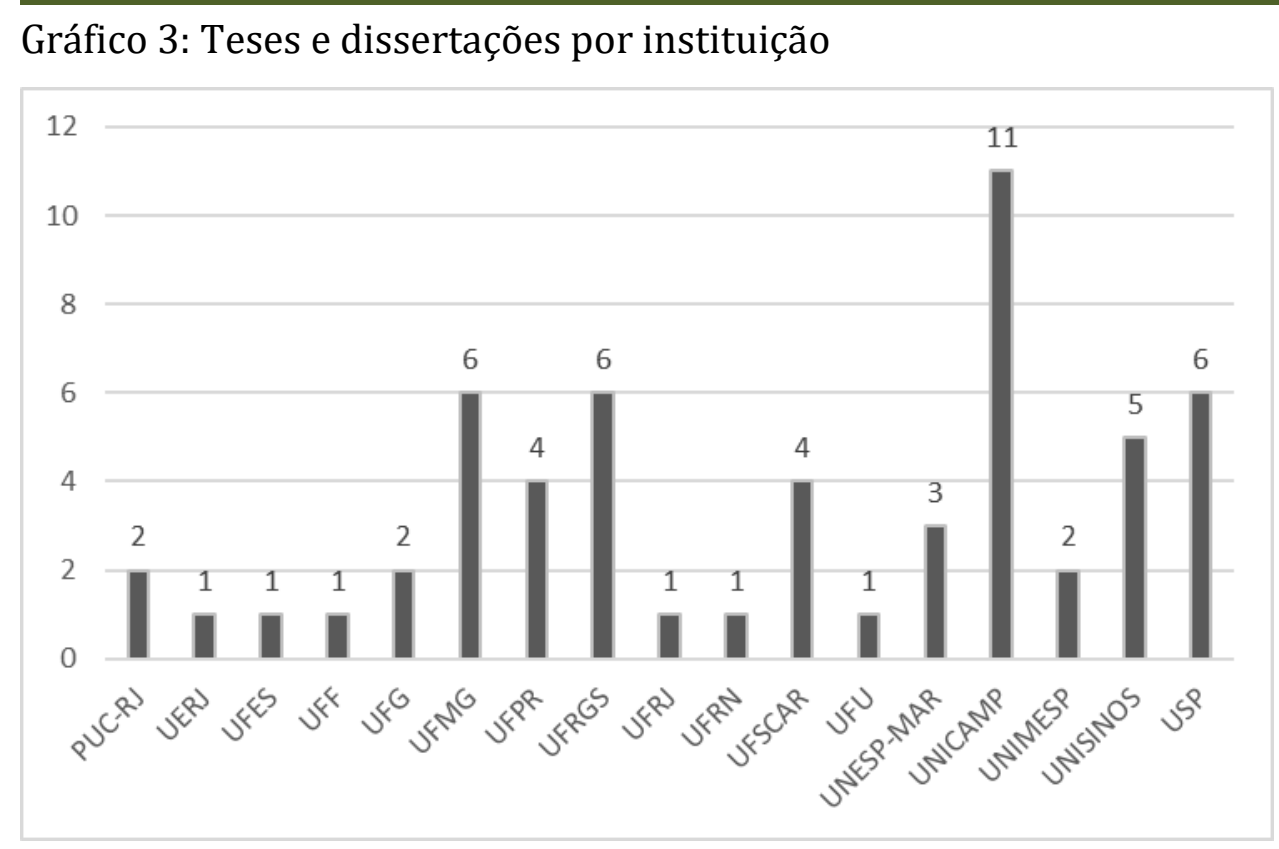

Fonte: SILVA (2014)

As Regiões Sul e Sudeste comparecem no topo dos estudos de mapeamento da produção brasileira desde a década de 1980, como evidenciado na pesquisa de Rocha, Silva Filho e Strenzel (2001). Já as Regiões Centro-Oeste, Norte e Nordeste correspondem a apenas 5,26\%. Contudo, cabe lembrar que o critério estabelecido na seleção dessas teses e dissertações foi terem sido defendidas em programas de pósgraduação em Educação que alcançaram o conceito 5 ou mais na avaliação trienal da Capes, concluída em 2010. Assim, esse dado não poderá ser tomado em valores absolutos e revela a necessidade da ampliação das investigações na área em universidades de diferentes regiões no país, especialmente no Centro-Oeste, Norte e Nordeste, que apresentaram apenas três estudos no período analisado.

Outra informação importante para delinear o cenário nacional das pesquisas sobre políticas públicas de educação infantil refere-se às cidades escolhidas como campo de pesquisa. A análise do Gráfico 4 reitera a tendência discrepante entre as regiões onde foram realizados os estudos, com destaque para o município de Porto Alegre, que obteve o maior número, com quatro estudos. Tal configuração pode ser caracterizada pela concentração de programas de pós-graduação nas regiões Sul e Sudeste. Somam-se a essas informações duas pesquisas de mestrado e uma de doutorado que contemplaram o estudo das políticas de educação infantil em vários municípios no mesmo estudo: uma que analisou cinco municípios do Vale do Jequitinhonha, em Minas Gerais, e outra que 
estudou 12 municípios na Região Metropolitana de Curitiba. A pesquisa de maior abrangência é uma tese de doutorado que agregou 77 municípios do Mato Grosso do Sul. Se somarmos esses números aos 27 municípios declarados nos resumos, teremos um total de 121 cidades brasileiras pesquisadas, o que representa 2,17\% das 5.570 existentes.

Gráfico 4 - Municípios onde a pesquisa foi realizada

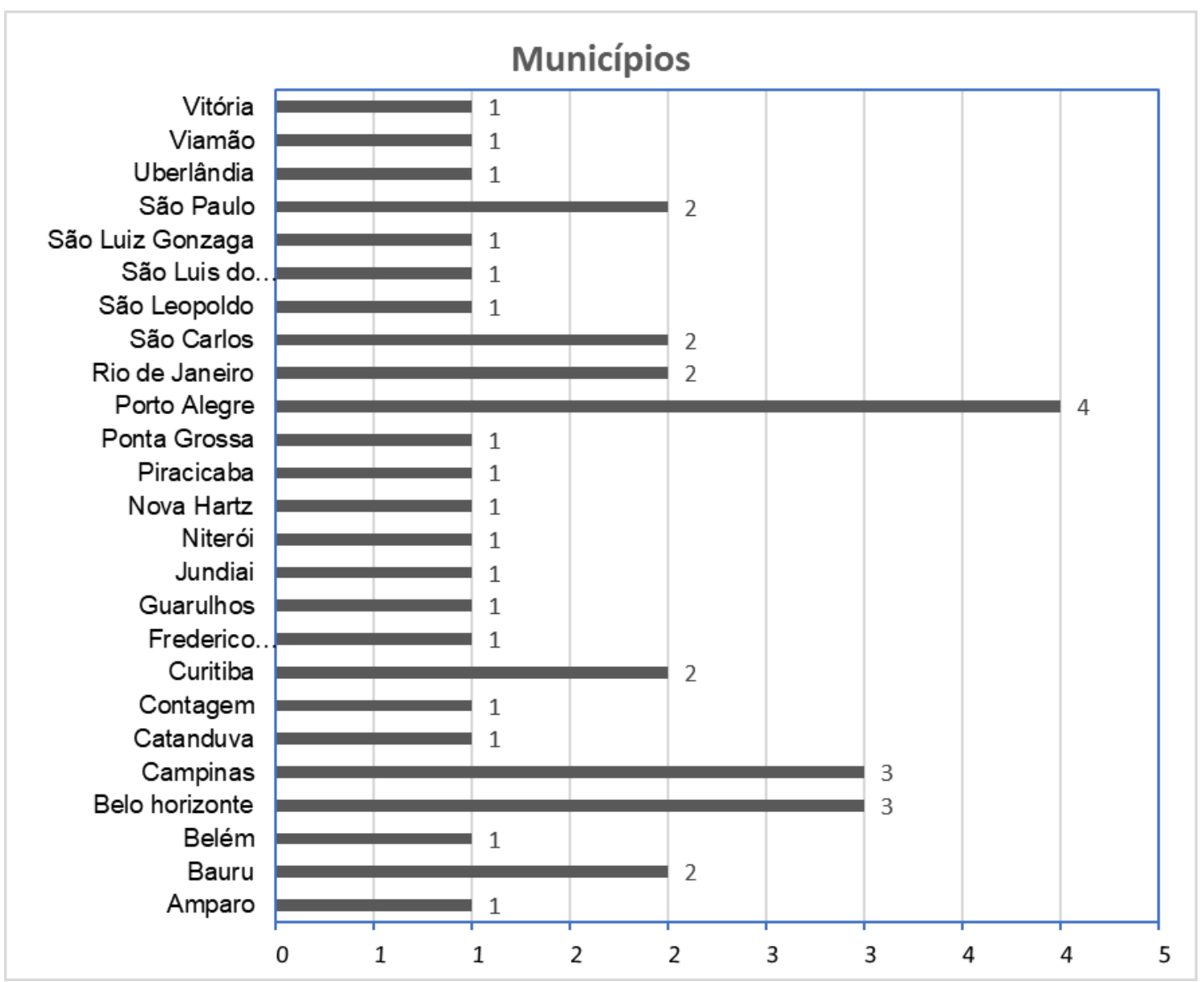

Fonte: SILVA (2014)

Tais constatações, ainda que relativizadas pelos limites do banco em análise, indicam a necessidade de ampliar os estudos sobre a temática para que abarquem maior número de municípios, por meio da constituição de projetos de pesquisa com financiamento que agreguem universidades em diferentes regiões do país, de modo a contribuir para a melhor compreensão da política brasileira de educação infantil.

De maneira geral, o conjunto dos trabalhos analisados tem como foco a implementação das políticas públicas de educação infantil e demonstra o movimento 
dos pesquisadores da primeira infância para compreender a área. 0 gráfico 5 indica os temas pesquisados.

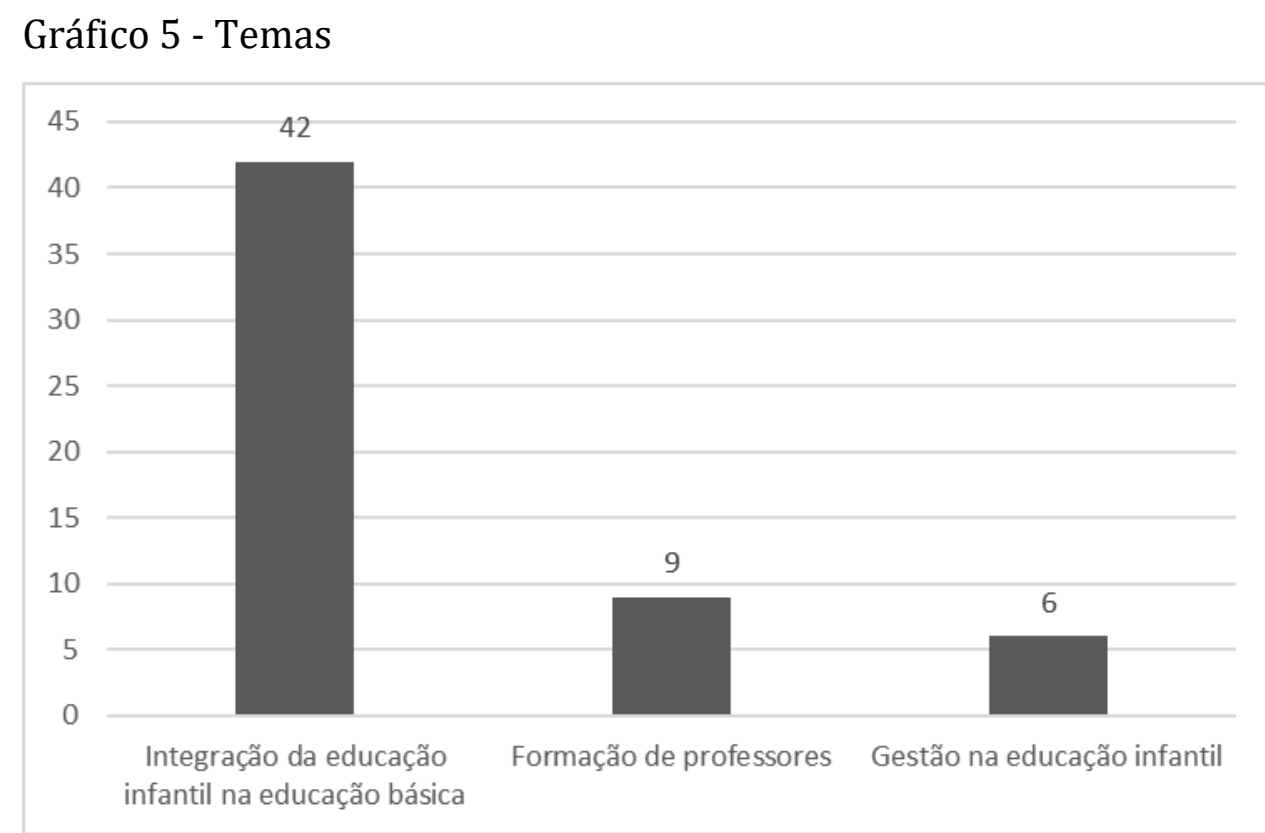

Fonte: SILVA (2014)

Destacam-se, a seguir, os principais resultados apresentados nos resumos a respeito dos temas: 1) Integração da educação infantil na educação básica; 2) Formação de professores; 3) Gestão na educação infantil.

\section{1) Integração da educação infantil na educação básica}

Dos 57 resumos, 37 investigaram diferentes dimensões do processo de integração da educação infantil como primeira etapa da educação básica, a partir da LDB. Desde então, as instituições de educação infantil passaram por um amplo processo de regulação, incluindo várias ações normativas que promoveram a inserção das creches aos sistemas de ensino municipais e a expansão da oferta.

A inserção das creches no sistema de ensino deu-se primeiramente com a movimentação nas diferentes cidades brasileiras, para deslocar administrativamente as creches da Secretaria de Assistência para a de Educação. Os cinco estudos que analisam a regulação e a incorporação das creches na educação constatam que, apesar das dificuldades com a transição, houve várias mudanças positivas no atendimento às crianças de 0 a 4 anos, como a organização da demanda, da gestão do sistema e das unidades e o investimento em formação que resultou na realização de programas 
especiais de formação inicial em magistério e curso superior em Pedagogia para as professoras leigas que atuavam nas creches.

Em alguns municípios houve também a criação de um setor na Secretaria de Educação para orientar os estabelecimentos de ensino quanto às novas normas administrativas de funcionamento das unidades de educação infantil. Considerando que o sistema de ensino brasileiro abrange o sistema público e o particular, os municípios têm como tarefa regular tanto as escolas públicas de educação infantil quanto as privadas. Duas pesquisas atentaram para a regulação das escolas de educação infantil privadas e constataram que muitas não possuíam autorização do Conselho Municipal de Educação, a exemplo do estudo de Porto Alegre, que constata ter, em 2007, apenas 6\% do total das escolas particulares da cidade autorizadas.

Os 29 trabalhos que abordam a expansão da oferta na educação infantil verificaram que ela aconteceu em todas as cidades analisadas, especialmente a partir da década de 1990, embora sejam recorrentes as considerações em torno da insuficiência de vagas diante da demanda, demonstrando que o direito à educação infantil não é plenamente efetivado em nenhum dos municípios pesquisados.

Os estudos comprovam a tendência histórica que permeia o atendimento em creches e pré-escolas brasileiras no que diz respeito à presença de dois tipos distintos de atendimento: o direto, mantido exclusivamente pelo Poder Público, e o conveniado, que compreende a participação do município por meio de subsídios financeiros e/ou disponibilização de prédios públicos para instituições não governamentais e filantrópicas organizarem e manterem as creches.

De acordo com Rosemberg (2002), a perspectiva de atendimento por meio de convênios tem, historicamente, respondido às demandas das agências internacionais e contribuído com a baixa qualidade das instituições de educação infantil em muitas situações, prejudicando o desenvolvimento da criança. Somando-se a esses estudos, Dominiciano, Franco e Adrião (2011) alertam-nos para um novo tipo de parceria entre poder público e instituições privadas, em que há investimento dos recursos públicos em instituições particulares não filantrópicas, tal como ocorreu em alguns municípios paulistas, em que escolas particulares que estavam em dificuldades para se manter no mercado foram beneficiadas por parcerias com as respectivas prefeituras.

Pode-se inferir, a partir dos resultados dos estudos analisados, que houve significativo aumento de vagas para crianças de 0 a 5 anos e 11 meses; entretanto, há 
questões de ordem estrutural, especialmente quanto às condições de trabalho dos educadores e às diferentes formas de atendimento, que podem resultar na baixa qualidade das instituições de educação infantil e, consequentemente, dificultar ou impedir a efetivação plena dos direitos das crianças pequenas. Embora três estudos do montante analisado demonstrem a ampliação do atendimento direto, a adoção da perspectiva neoliberal para organização das políticas públicas de educação infantil efetiva uma clara tendência da expansão do atendimento conveniado em detrimento do direto (CORREIA, 2013; DIAS, 2017). Nesse sentido, o aprofundamento de pesquisas sobre as diferenças entre o atendimento público e o conveniado ou parceria públicoprivado, no contexto atual, coloca-se como tema relevante que merece ser ampliado no campo das políticas educacionais para a primeira infância.

Como afirmamos acima, em apenas três trabalhos foi evidenciada como avanço, além da expansão das vagas, a constituição do atendimento público, atenuando a presença do terceirizado. Apesar disso, indicam-se também as fragilidades: a construção das unidades educacionais distantes da residência das famílias mais pobres e a baixa remuneração dos educadores, o que traz constante alteração do quadro de profissionais; em alguns casos, a criação de cargos com denominações diferentes para atuar junto à criança - como "educador infantil" - provocou o aumento da precarização das condições de trabalho das docentes de educação infantil, especialmente por apresentar condições salariais e jornada de trabalho diferenciada de outras etapas da educação básica ou da própria educação infantil.

A precarização do atendimento também foi evidenciada na pesquisa que investigou as políticas públicas de educação infantil brasileira subsidiadas pelo Banco Mundial (BM). Conclui-se que a materialização das proposições do BM ocorreu no país desde a década de 1990, momento em que a educação de 0 a 6 anos foi pauta na agenda do banco sob uma visão economicista, que buscou reduzir gastos públicos e implementar programas de baixo custo com características informais. A influência internacional foi constatada no Brasil já na década de 1960, em âmbito regional, no estudo sobre as práticas pedagógicas nos jardins de infância do Paraná e a influência dos Estados Unidos por meio da Organização das Nações Unidas para Educação, Ciência e Cultura (Unesco), traduzida em uma formação para crianças pautada no civismo e no amor ao trabalho. 
Por longo período, o atendimento nas creches brasileiras ocorreu por meio de entidades filantrópicas; o Estado assumiu vagarosamente o atendimento direto a partir do final da década de 1970, especialmente por conta da pressão dos movimentos sociais para a construção de creches. Pelos estudos analisados pode-se considerar que na década de 1990 foi inaugurada uma nova etapa da expansão da oferta, com aumento significativo de matrículas, mas a configuração apresenta contornos acentuados dos princípios neoliberais presentes nas propostas de reforma do Estado daquela época, que reforçam tendências de precarização do atendimento presentes nas décadas de 1970 e 1980. Os pressupostos da descentralização e da privatização são indicadores assinalados pelos estudos, que afirmam a tendência do Estado a responder às demandas pela garantia do direito à educação infantil sob forte influência das ordenações neoliberais, gerando impactos negativos na estrutura, financiamento e formação de professores e priorizando declaradamente o investimento no ensino fundamental.

Segundo Rosemberg (2002), a perspectiva adotada no governo do presidente Fernando Henrique Cardoso (1995-2003), pautada nas orientações do BM, desconsiderou esforços realizados na construção de novas bases para as políticas públicas de educação infantil ao retomar propostas de programas não formais, com baixo investimento público e com condições precárias de atendimento, adjetivadas por Franco (1989) como "atendimento pobre para pobre". Tal perspectiva foi estimulada especialmente nos países subdesenvolvidos em que a Unesco e o Fundo das Nações Unidas para a Infância (Unicef) recomendavam a ampliação do atendimento para crianças de 0 a 6 anos, nos moldes barateados e de caráter comunitário, nomeados por Rosemberg (2002, p. 52) como "uma educação para a subalternidade". Tal proposição denunciada pela pesquisadora é evidenciada em um dos estudos analisados, que investigou a revista Criança no período de 1982 a 1985, concluindo que o periódico, de abrangência nacional, disseminava concepções político-pedagógicas baseadas na ação voluntária, no esforço da comunidade, no baixo investimento público, na remuneração simbólica dos monitores e no aproveitamento de sucata e de espaços ociosos.

Dois trabalhos do banco de dados analisado tratam de programas e projetos de cunho intersetorial. Em suas conclusões, destacam a inovação de projetos que colocam os direitos das crianças como eixo norteador para a constituição de uma política de atendimento, incentivam a mobilização popular e destacam, como um dos empecilhos para a constituição de uma política integrada, as dificuldades em promover a articulação 
entre diferentes órgãos responsáveis, especialmente quando tais programas são inseridos no cotidiano das escolas de educação infantil e impactam diretamente a atuação dos docentes. Embora nos resumos desses trabalhos não haja dados para analisar a natureza dos projetos, é preciso atentar que as crianças de 0 a 6 anos têm sido foco de atenção de setores da sociedade que incentivam e financiam diferentes projetos de cunho intersetorial, com interface com o setor público, a maioria com presença marcante de concepções economicistas e referenciais neoliberais (ROSEMBERG, 2002).

Há dois estudos que evidenciam outra particularidade da ampliação da oferta. 0 primeiro trata sobre um modelo de atendimento em educação infantil denominado Educriança, destinado a suprir a deficiência de vagas para 0 a 3 anos, centrado no processo de formação das mães e realizado em âmbito familiar, mas não apresenta os resultados. 0 segundo, pesquisa as creches nas universidades públicas paulistas que, tal como nas creches implantadas pelo governo municipal, citadas nos outros estudos aqui analisados, não conseguem ofertar vagas suficientes para todos os filhos de funcionários, professores e estudantes.

Entre os estudos sobre ampliação da oferta situam-se os que abordam o financiamento, os quais ocupam lugar ínfimo diante de sua importância para legitimar o direito à educação infantil das crianças de 0 a 5 anos e 11 meses. 0 fato de apenas quatro trabalhos, do montante de 57, ater-se a essa temática configura-se com uma das lacunas dos estudos na área.

De modo geral, as quatro pesquisas assinalam a aplicação de subsídios financeiros para a educação infantil a partir da década de 1990 e o empenho dos governos municipais em destinar recursos para a manutenção e ampliação da educação infantil; mas, apesar desse esforço, a demanda atendida é muito aquém do que a efetiva, e cada cidade adota diferentes estratégias para promover e expandir esse nível educacional. Destacamos uma pesquisa de mestrado realizada na rede de creches do município de São Paulo que, apesar de não apresentar resultados no resumo, aborda uma temática importante, pois analisa o montante de recursos necessários para universalizar e atender com qualidade. Tal exercício é de fundamental importância para conciliarmos o binômio expansão e qualidade.

No banco de dados analisado, a temática da qualidade é abordada em apenas três estudos, que apontam de maneira geral para a existência de compreensões diferentes 
sobre qualidade entre as escolas pesquisadas e a necessidade de avançar com relação à universalização da oferta e à disponibilização de recursos financeiros.

Documentos elaborados pelo Ministério da Educação (BRASIL, 2006, 2009; CAMPOS; ROSEMBERG, 2009) servem como norteadores para a implementação de políticas públicas de educação infantil com qualidade, a fim de atenuar graves problemas de infraestrutura, desqualificação docente, falta de diretrizes pedagógicas e dificuldades na comunicação com as famílias, que colocam em risco o desenvolvimento das crianças e negligenciam seus direitos fundamentais nas diferentes regiões do Brasil (CAMPOS; FÜLLGRAF; WIGGERS 2006).

Um importante elemento apontado em um dos estudos foi a necessidade de diálogo entre conselhos tutelares, famílias e escolas com relação à demanda e à oferta, para fazer valer os direitos das crianças. 0 resumo não traz os resultados da pesquisa, mas destaca a necessidade de considerar crianças e adolescentes como sujeitos de direitos em desenvolvimento, articular esforços em prol desses direitos, reorganizar a política setorial para o segmento e garantir a reestruturação da conjuntura política dos órgãos, de modo a efetivar o acesso às escolas próximas à residência dos alunos.

O diálogo entre famílias, escola e conselho tutelar é componente significativo a ser compreendido devido à atual tendência de ampliação de vagas por meio da judicialização (ASSIS; PEREZ, 2013; INAFUKU, 2017; SILVEIRA, 2012). No banco de dados estudado, o assunto foi abordado de maneira indireta em uma pesquisa cujo objeto de estudo foi a garantia de acesso e a demanda reprimida na educação infantil em 77 municípios do Mato Grosso do Sul. Verificou-se a presença de solicitações de vagas no Sistema de Informação para Infância e Adolescência e Conselhos Tutelares e uma ação civil pública da Promotoria da Infância contra a prefeitura de Campo Grande, por falta de vagas em creche. A judicialização para a expansão da oferta na educação infantil é mais um aspecto que precisa ser mais pesquisado.

Finalmente, encontramos cinco estudos de políticas mais amplas que, apesar de não se restringirem ao processo de integração da educação infantil na educação básica, versam sobre diferentes aspectos da construção e implementação da política e sua interface histórica, estrutural e pedagógica em contextos e tempos específicos. Os principais resultados desses estudos destacam os debates sobre a proteção à criança, a capacidade do Estado de responder aos problemas da infância e as tensões relacionadas 
à educação da criança pequena: educação da criança fora da família, reponsabilidade e função, liberação da mãe para o trabalho versus desenvolvimento da criança.

Diante desse cenário, em que a ampliação da oferta apresenta discrepâncias entre os direitos das crianças previstos na legislação e as políticas implementadas, é necessário avançar para além do direito ao acesso e qualificar a oferta educacional em creches e pré-escolas, situando a criança no centro das reflexões (CAMPOS; MACHADO, 2006).

\section{2) Formação de professores}

Os debates sobre a formação de profissionais de educação infantil (KISHIMOTO, 2004; KRAMER, 2005; KRAMER; NUNES, 2007) inserem-se em questões e tensões de natureza econômica e política e de natureza social e cultural. As primeiras dizem respeito ao paradoxo entre as prerrogativas legais da formação e a realidade do atendimento em creches e pré-escolas (condições objetivas de trabalho, equipamentos inadequados, não articulação entre carreira e salários, não disponibilização de tempo para estudos e reuniões em sua carga horária de trabalho); as segundas referem-se à condição feminina, ao papel sexual, reprodutivo, desempenhado tradicionalmente pelas mulheres, associado às atividades do magistério infantil, que remetem à falta de formação especializada e à desvalorização do trabalho com a criança de 0 a 5 anos.

Os nove resumos analisados versaram sobre programas de formação inicial e continuada, impactos da formação continuada nas práticas cotidianas, constituição da identidade do professor de educação infantil e condições de trabalho.

Os resultados dos estudos sobre políticas de formação continuada de professores de educação infantil indicaram algumas fragilidades: a concepção de formação adotada pelo município, que nem sempre atende às necessidades de formação dos professores, especialmente com relação ao espaço e ao tempo de formação; falta de aprofundamento teórico e descontinuidades nos programas e ações de formação; insuficiência e baixa qualidade na oferta; desarticulação entre política de formação e política salarial. Os trabalhos enfatizam a necessidade de uma política de formação que busque ouvir os profissionais, para constituir projetos coadunados com as proposições teóricas no âmbito da universidade, e a necessidade de contemplar com profundidade as reflexões sobre concepções de criança, infância e educação infantil e articular o saber da experiência ao teórico, como elemento importante para potencializar a reflexão sobre a 
identidade docente. Apenas um estudo analisou o programa Formação Universitária Municípios (PEC), considerando-o promotor de uma sólida formação teórica de professores de educação infantil.

Duas pesquisas detectaram não haver impacto da formação continuada nas práticas cotidianas escolares quando o investimento é insuficiente para favorecer a repercussão na prática do professor, seja por não haver continuidade nas propostas de formação, seja pela não disponibilização de recursos para a compra de materiais didáticos. Já quando há investimento e uma proposta bem articulada, após a participação nas formações, os docentes se fortalecem para o desenvolvimento de atividades inovadoras e assumem postura ativa junto à construção de novas metodologias e do projeto político-pedagógico (PPP).

Historicamente, a educação infantil brasileira tenta desvencilhar-se das perspectivas preparatórias e compensatórias presentes na pré-escola, do caráter tutelar e substitutivo da creche e da dicotomia entre o cuidar e o educar. Assim, as formações de professores têm sido espaço privilegiado para a divulgação de novas perspectivas ancoradas na necessidade de superação das relações hierárquicas que se estabelecem entre profissionais com distintos níveis de escolaridade no mesmo espaço de trabalho, da especificidade do trabalho na educação infantil, da profissionalidade docente e do desenvolvimento profissional, que consideram a criança e seu desenvolvimento em contextos coletivos e suas múltiplas linguagens como centro do processo educativo.

Desse modo, tal como na análise das pesquisas apresentadas e nos estudos de Kishimoto (2004), Kramer (2005) e Kramer e Nunes (2007), notam-se discrepâncias entre as propostas de formação e sua efetivação, o que indica a necessária superação de desafios para a efetivação de políticas de formação articuladas e abrangentes, que integrem as vozes, os saberes e as vivências profissionais dos docentes sem desconsiderar as vozes das crianças.

\section{3) Gestão na educação infantil}

A temática da gestão na educação infantil é atualmente uma lacuna nos estudos sobre administração escolar, visto que a maioria das pesquisas se concentra no ensino fundamental (FERNANDES; CAMPOS, 2015). Dos resumos analisados, seis abordam a temática, com foco na administração das unidades de educação infantil - especialmente 
no que concerne ao desenvolvimento do PPP -, na compreensão sobre gestão democrática, na atuação dos diretores e na participação infantil na gestão.

Os estudos que versam sobre a gestão nas instituições de educação infantil, considerando as estratégias para estimular a autonomia e a participação por meio da construção do PPP, assinalam que o processo de democratização não se concretiza em sua totalidade com a elaboração coletiva do PPP, mas nesse processo é possível avançar e identificar possibilidades e desafios.

De maneira geral, as pesquisas acerca do papel do diretor e suas aprendizagens indicam que as aprendizagens se situam, especialmente, no que se refere a trabalho coletivo, liderança, mediação de conflitos e tomadas de decisão e na sobreposição das atividades burocráticas às ações pedagógicas no cotidiano.

Com relação à organização e gestão da escola na perspectiva democrática, é evidenciado que a gestão democrática tem se concretizado com muitas dificuldades a partir da determinação legal na CF/88. Nesse sentido, apesar de serem recorrentes as discussões da área com relação à centralidade da criança no processo educativo (CONSELHO NACIONAL DE EDUCAÇÃO, 2009) e à necessidade de atentar para a democratização das relações entre educandos e educadores, compreendendo-a como um dos pilares da gestão educacional democrática (PARO, 2001), apenas um trabalho tomou como foco de estudo a participação infantil. Nele se destaca a importância dessa participação na gestão das unidades de educação infantil, a necessidade de descentralizar o poder dos adultos e considerar as instituições como um espaço público para as crianças, por estas serem capazes de participar nas práticas sociais e pedagógicas.

As características dos estudos analisados direcionam à ampliação de conhecimentos sobre os contextos institucionais, mas, pela restrição imposta pela análise dos resumos, pouco pôde ser identificado quanto a novos elementos que desvelem a especificidade da gestão na educação infantil. Isso remete à necessidade de novas incursões, a fim de aprofundar aspectos tanto do cotidiano das instituições, para efetivar a democratização - como a participação de todos os atores, inclusive das crianças -, quanto da análise da gestão das redes de educação infantil. 


\section{Considerações finais}

Este artigo soma-se às investigações sobre o campo da política educacional (BELLO; JACOMINI; MINHOTO, 2014; SOUZA, 2014; MAINARDES; TELLO, 2016; SILVA; SCAFF; JACOMINI, 2016) e assinala a necessidade de estudos de revisão que contribuam para o avanço do conhecimento sobre políticas educacionais, por meio da análise da produção de conhecimentos sobre o campo.

A análise dos resumos, no universo estudado, indicou a existência de poucos estudos sobre políticas públicas de educação infantil, mostrando a necessidade de ampliá-los, por meio da constituição de grupos de pesquisa que agreguem pesquisadores de diferentes universidades e possibilitem constituir um panorama abrangente, tanto da oferta e sua qualidade quanto da demanda de vagas para crianças de 0 a 5 anos e 11 meses.

Verificou-se a expansão da oferta no período considerado bem como mudanças positivas no atendimento das crianças, tanto na organização e gestão dos sistemas e das unidades quanto na formação de professores, embora a expansão não tenha sido acompanhada de qualidade. Em consequência, o direito da criança pequena à educação infantil de qualidade ainda não foi efetivado. Entre as razões para isso, estão: insuficiência de vagas, descompasso entre as propostas de políticas e sua efetivação, precárias condições de trabalho dos docentes, incipiência da gestão democrática, financiamento ínfimo, políticas de formação de professores descontínuas e com pouco impacto no cotidiano das instituições.

Outra constatação diz respeito à manutenção do processo histórico de atendimento nas creches brasileiras por convênios e à precarização do atendimento das crianças dessa faixa etária na educação infantil, assim como das condições de trabalho dos profissionais, especialmente os não docentes. É digno de nota que a maioria dos trabalhos indica a forte presença da influência dos organismos internacionais no Brasil, que desde a década de 1970 orientam a expansão do atendimento à criança pequena a baixo custo como via de combate à pobreza e melhora do desempenho no ensino fundamental.

Isso posto, reiteramos a necessidade de envidar esforços para qualificar a produção de conhecimentos na área, a fim de contribuir para a concretização do acesso com qualidade e considerar a especificidade das crianças pequenas como ponto de partida para políticas que respeitem seus direitos. 
No conjunto dos 57 trabalhos, apenas um destacou como conclusão a necessidade de as políticas públicas de educação infantil terem como eixo central a criança, a infância e suas lógicas. A criança pequena, suas especificidades e direitos fundamentais, foram pouco destacados nos resumos, sendo um dos elementos importantes para uma análise mais aprofundada dos estudos aqui apresentados, de modo a constatar se a proposição da centralidade da criança tem sido considerada nas estratégias de implementação das políticas de educação infantil.

\section{Referências}

ASSIS, Ana Elisa Spaolonzi Queiroz; PEREZ, José Roberto Rus. Justiça social e política educacional: extensão das vagas escolares na educação infantil. Revista Educação PUCCampinas, Campinas, v. 18, n. 2, p.161-169, maio/ago. 2013.

BELLO, Isabel Merelo; JACOMINI, Márcia Aparecida; MINHOTO, Maria Angélica Pedra. Pesquisa em política educacional no Brasil (2000-2010): uma análise de teses e dissertações. Práxis Educativa (UEPG online), v. 9, p. 369-393, 2014.

BRASIL. Constituição (1988). Constituição da República Federativa do Brasil: promulgada em 5 de outubro de 1988. Brasília, DF, 1988.

BRASIL. Lei no 9.394, de 20 de dezembro de 1996. Estabelece as diretrizes e bases da educação nacional. Diário Oficial da União, Brasília, DF, 23 dez. 1996. Disponível em: <http://www.planalto.gov.br/ccivil_03/leis/19394.htm>. Acesso em: 24 jun. 2018.

BRASIL. Ministério da Educação. Secretaria de Educação Básica. Indicadores da qualidade na educação infantil. Brasília, DF: MEC/SEB, 2009.

BRASIL. Ministério da Educação. Secretaria de Educação Básica. Parâmetros nacionais de qualidade para a educação infantil. 2 v. Brasília, DF: MEC/SEB, 2006.

CAMPOS, Maria Malta; FÜLLGRAF, Jodete; WIGGERS, Verena. A qualidade da educação infantil brasileira: alguns resultados de pesquisa. Cadernos de Pesquisa, São Paulo, v. 36, n. 127, p. 87-128, 2006.

CAMPOS, Maria Malta; HADDAD, Lenira. Educação infantil: crescendo e aparecendo. Cadernos de Pesquisa, São Paulo, n. 80, p. 11-20, fev. 1992.

CAMPOS, Maria Malta; MACHADO, Maria Lúcia. Consulta sobre qualidade na educação infantil: o que pensam e querem os sujeitos deste direito. São Paulo: Cortez, 2006.

CAMPOS, Maria Malta; ROSEMBERG, Fúlvia. Critérios para um atendimento em creches que respeite os direitos fundamentais das crianças. 6. ed. Brasília, DF: MEC/SEB, 2009.

CONSELHO NACIONAL DE EDUCAÇÃO. Câmara de Educação Básica. Resolução no 5, de 17 de dezembro de 2009. Fixa as diretrizes curriculares nacionais para a educação infantil. Brasília, DF, 2009. Disponível em: <http://portal.mec.gov.br/index.php?option=com_content\&view=article\&id=13684\%3 Aresolucoes-ceb>. Acesso em: 24 jun. 2018. 
CORREIA, Maria Aparecida Antero. Educação infantil de 0 a $\mathbf{3}$ anos: um estudo sobre demanda e qualidade na região de Guaianazes, São Paulo. 2013. Dissertação (Mestrado em Educação) - Faculdade de Educação, Universidade de São Paulo, São Paulo, 2013.

DIAS, Suely Rispamonti Calazans. 0 papel da equipe gestora na organização do trabalho pedagógico nas creches conveniadas do município de São Paulo. 2017. Dissertação (Mestrado em Educação) - Universidade Cidade de São Paulo, São Paulo, 2017.

DOMICIANO, Cássia Alessandra; FRANCO, Dalva de Souza; ADRIÃo, Theresa. Educação infantil de zero a três anos. Revista Retratos da Escola, Brasília, DF, v. 5, n. 9, p. 309-327, jul./dez. 2011.

FARIA, Ana Lúcia Goulart de. Política de regulação, pesquisa e pedagogia na educação infantil, primeira etapa da educação básica. Educação e Sociedade, Campinas, v. 26, n. 92 - Especial, p. 1.013-1.038, out. 2005.

FERNANDES, Fabiana Silva; CAMPOS, Maria Malta. Gestão na educação infantil: um balanço de literatura. Educação em Revista, Belo Horizonte, v. 31, n. 1, p. 139-167, jan./mar. 2015.

FRANCO, Maria A. Ciavatta. Lidando pobremente com a pobreza: análise de uma tendência no atendimento a crianças "carentes" de 0 a 6 anos de idade. In: ROSEMBERG, Fúlvia (Org.). Creches. São Paulo: Cortez, 1989. p. 179-215.

INAFUKU, Marcela. A expansão de vagas em creches: a complexidade do diálogo entre o poder judiciário e a administração pública. Dissertação (Mestrado profissional Formação de Gestores Educacionais) - Programa de Pós-Graduação em Educação, Universidade Cidade de São Paulo, São Paulo, 2017.

KISHIMOTO, Tizuko M. O sentido da profissionalidade para o educador da infância. In: BARBOSA, Raquel Lazarri L. (Org.). Trajetórias e perspectivas da formação de educadores. São Paulo: Edunesp, 2004. p. 329-345.

KRAMER, Sonia. Formação de profissionais de educação infantil: questões e tensões. In: MACHADO, Maria Lúcia de A. (Org.). Encontros e desencontros em educação infantil. 2. ed. São Paulo: Cortez, 2005. p. 117-132.

KRAMER, Sonia; NUNES, Maria Fernanda. Gestão pública, formação e identidade de profissionais de educação infantil. Cadernos de Pesquisa, São Paulo, v. 37, n.131, p. 423-454, ago. 2007.

MAINARDES, Jefferson; TELLO, C. A pesquisa no campo da Política Educacional: explorando diferentes níveis de abordagem e abstração. Archivos Analíticos De Políticas Educativas / Education Policy Analysis Archives, v. 24, p. 1-17, jul. 2016. Disponível

em: $<$ https://www.researchgate.net/publication/305348695_A_Pesquisa_no_Campo_da_Pol itica_Educacional_Explorando_Diferentes_Niveis_de_Abordagem_e_Abstracao $>$. Acesso em: 25 jun. 2018.

PARO, Vitor Henrique. Escritos sobre educação. São Paulo: Xamã, 2001.

ROCHA, Eloisa Acires Candal. A pesquisa em educação infantil no Brasil: trajetória recente e perspectivas de consolidação de uma pedagogia. 1999. Tese (Doutorado em Educação) - Faculdade de Educação, Universidade Estadual de Campinas, Campinas, 1999. 
ROCHA, Eloisa Acires Candal; SILVA FILHO, João Josué da; STRENZEL, Giandréa Reuss (Org.). Educação infantil (1983-1996). Coordenação de Eloisa Acires Candal Rocha. Brasília, DF: MEC/Inep/Comped, 2001. (Série Estado do Conhecimento, 2). Disponível em:

<http://download.inep.gov.br/download/cibec/2001/estado_do_conhecimento/serie_d oc_educacao_infantil.pdf>. Acesso em: 24 jun. 2018.

ROSEMBERG, Fúlvia. Organizações multilaterais, Estado e políticas de educação infantil. Cadernos de Pesquisa, São Paulo, n. 115, p. 25-63, 2002.

ROSEMBERG, Fúlvia. Políticas públicas e qualidade da educação infantil. In: SANTOS, Marlene Oliveira dos; RIBEIRO, Maria Izabel Souza (Org.). Educação infantil: os desafios estão postos: e o que estamos fazendo? Salvador, Sooffset, 2014.p.169-185.

SILVA, Antonia Almeida (Coord.). A produção acadêmica em políticas educacionais no Brasil: características e tendências (2000-2010). [banco de dados]. Feira de Santana: Universidade Estadual de Feira de Santana, 2014. Disponível em: <http://www2.uefs.br/cede/apresentacao-bd.html>. Acesso em: 25 jun. 2018.

SILVA, Antonia Almeida; JACOMINI, Márcia Aparecida; SCAFF, Elisangela A. S. Políticas públicas e políticas educacionais: percursos históricos, interfaces e contradições das produções na década de 2000. Revista HISTEDBR, on-line, v.16, p.254-273, 2016.

SILVEIRA, Adriana Aparecida Dragone. Atuação do Tribunal de Justiça de São Paulo com relação ao direito de crianças e adolescentes à educação. Revista Brasileira de Educação, Rio de Janeiro, v. 17, n. 50, p. 353-497, 2012.

SOUZA, Ângelo Ricardo de. A pesquisa em política educacional no Brasil: de que estamos tratando? Práxis Educativa (UEPG Online), v.9, p.355-367,2014.

STRENZEL, Giandréa Reuss. A produção científica sobre educação infantil no Brasil nos programas. de pós-graduação em Educação. In: REUNIÃO ANUAL DA ANPED, 23., 24-28 set. 2000, Caxambu. Anais eletrônicos... Rio de Janeiro: ANPED, 2000. Disponível em: <http://23reuniao.anped.org.br/textos/0710t.PDF>. Acesso em: 2 jun. 2018.

VOSGERAU, Dilmeire Sant'anna Ramos; ROMANOWSKI, Joana Paulin. Estudos de revisão: implicações conceituais e metodológicas. Revista Diálogo Educacional, Curitiba, v. 14, n. 41, p. 165-189, jan./abr. 2014. 

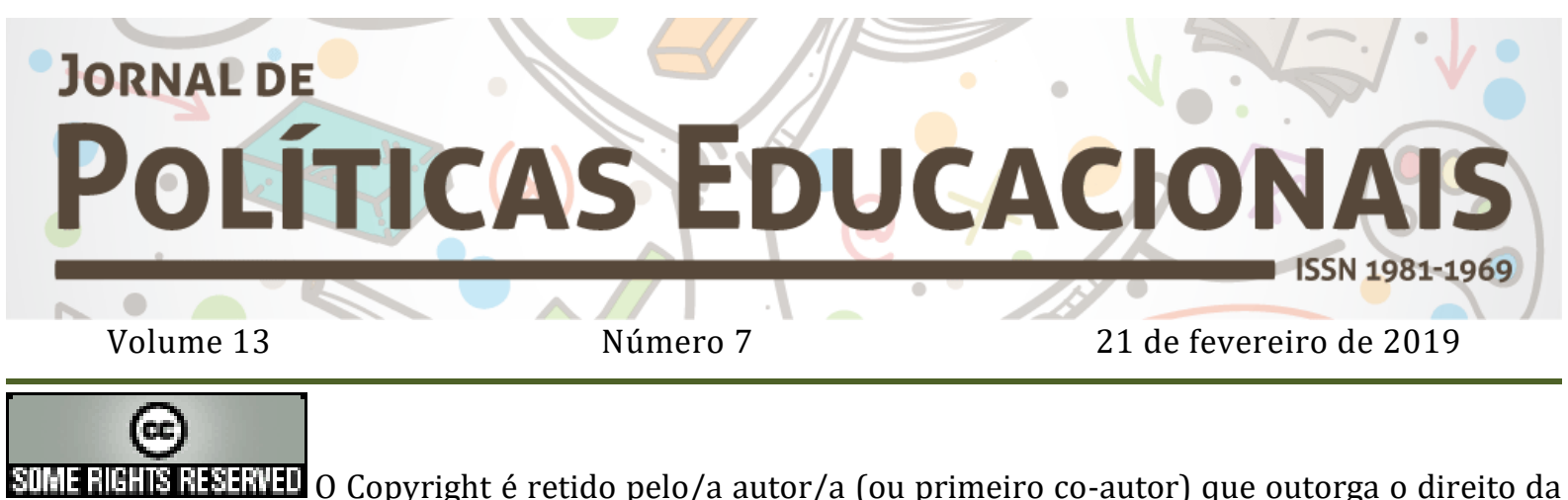

0 Copyright é retido pelo/a autor/a (ou primeiro co-autor) que outorga o direito da primeira publicação ao Jornal de Políticas Educacionais. Mais informação da licença de CreativeCommons encontram-se em http://creativecommons.org/licenses/by-nc-nd/2.5. Qualquer outro uso deve ser aprovado em conjunto pelo/s autor/es e pelo periódico.

Jornal de Políticas Educacionais é uma publicação do Núcleo de PolíticasEducacionaisdo Setor de Educação da Universidade Federal do Paraná - NuPE/UFPR, em consórcio com a Linha de Pesquisa em Políticas Educacionais do Programa de Pós-Graduação em Educação - PPGE/UFPR, que aceita colaboração, reservando-se o direito de publicar ou não o material espontaneamente enviado à redação. As colaborações devem ser enviadas ao NuPE/UFPR, conforme orientações contidas nas páginas do periódico na internet: http://revistas.ufpr.br/jpe.

\author{
Indexação: \\ BBE - Biblioteca Brasileira de Educação (MEC/INEP) \\ Clase (Base de Datos Bibliográfica de Revistas de Ciencias Sociales y Humanidades) \\ Diadorim - Diretório de Política de Acesso Aberto das Revistas Científicas Brasileiras (IBICT) \\ Google Scholar \\ Index Copernicus \\ Portal de Periódicos (CAPES) \\ SER - Sistema Eletrônico de Revistas da Universidade Federal do Paraná (SER/UFPR) \\ Sumários de Revistas Brasileiras (FUNPEC-RP) \\ DRJI - Directory of Research Journals Indexing
}

(Periódico integralmente disponível apenas em via eletrônica)

Jornal de Políticas Educacionais / Núcleo de Políticas Educacionais da Universidade Federal do Paraná -

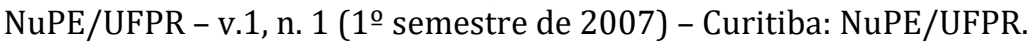

Volume 13, número 7 - Fevereiro de 2019

ISSN 1981-1969

1. Educação - Periódicos. 2. Política Educacional - Periódicos. I. NuPE/UFPR

Comitê Editorial:

Elisângela Scaff (UFPR)

Ana Lorena Bruel (UFPR)

Gabriela Schneider (UFPR)

Conselho Editorial:

Andréa Barbosa Gouveia (UFPR), Ângela Hidalgo (UNICENTRO), Cesar GernominoTello (Universidad Nacional TresFebrero, Argentina),Gladys Beatriz Barreyro (USP), Juca Gil (UFRGS), Jefferson Mainardes 
(UEPG), João Ferreira de Oliveira (UFG), Luiz Souza Júnior (UFPB), Marcos Edgard Bassi (UFSC), Regina Maria Michelotto (UFPR), Robert Verhine (UFBA), Rosana Cruz (UFPI), Rubens Barbosa Camargo (USP), Sebastián Donoso Díaz (Universidad de Talca, Chile), Taís Moura Tavares (UFPR), TheresaAdrião (UNICAMP), Vera Peroni (UFRGS).

Créditos e Agradecimentos:

Revisão de Língua Portuguesa, Abstract e Resumen: PROGRAMA DE APOIO ÀS PUBLICAÇÕES CIENTÍFICAS PERIÓDICAS DA UFPR

Arte e diagramação: TIAGO TAVARES (tiagotav@gmail.com)

Jornal de Políticas Educacionais

Universidade Federal do Paraná

Setor de Educação

Núcleo de Políticas Educacionais - NuPE/UFPR

Avenida Sete de Setembro, 2645

$2^{\circ}$ andar, Sala 213

80.230-010 - Curitiba - PR - Brasil

Tel.: 41-3535-6264

jpe@ufpr.br

http://revistas.ufpr.br/jpe 